\title{
Moralistic Gods and Social Complexity: A Brief History of the Problem
}

\author{
Benjamin Grant Purzyckia and Ryan McKayb \\ ${ }^{a}$ Aarhus University

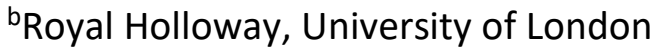

\begin{abstract}
A cluster of persistent and contentious questions in the scientific study of religion concern when and why so-called "moralistic traditions" developed and how they have shaped human relationships. Is there an association between moralistic gods and the size and/or complexity of the society that might worship them? How cross-culturally ubiquitous are such traditions? Are people more willing to engage in cooperative behavior when they believe their god cares about morality? This chapter focuses on how these questions have arisen and how generations of researchers have struggled to address them. We first briefly examine the intellectual history of the problem, pointing to some of the troubling aspects of early observations of traditional societies and subsequent anthropological positions. We then address how early observations of small-scale peoples have populated cross-cultural resources that have informed and driven contemporary empirical projects. We finish by pointing to ways in which we might go about ensuring that the conversation continues with clarity and consistency.
\end{abstract}

\section{An Historical View of Moralistic Gods}

Much of our knowledge of past traditional populations comes from missionary sources and explorers. As we discuss below, these sources populate the databases contemporary researchers use to examine patterns in human behavior. While many of these sources provide considerable knowledge about traditional peoples, they are not without problems, particularly in their documentation of traditional religions. In fact, historically, many observers simply denied that traditional peoples even had religion in the first place, thus clouding much of what we could have known.

For example, Christopher Columbus posited that the Canary Islanders "would become Christians very easily, for it seemed to [him] that they had no religion" (Dunn and Kelley, Jr. 1989: 69). Similarly, one missionary (Dobrizhoffer 1822) who worked among the Abipón Indians of Paraguay argued that "the American savages are slow, dull, and stupid in the apprehension of things not present to their outward senses. Reasoning is a process troublesome and almost unknown to them. It is, therefore, no wonder that the contemplation of terrestrial or celestial objects should inspire them with no idea of the creative Deity, nor indeed of any thing heavenly" (p. 58; emphasis ours). After "eighteen years spent amongst the Guaranies, and Abipones", the author professed to "having myself seen most barbarous savages born in the woods, accustomed from their earliest age to superstition, slaughter, and rapine, and naturally dull and stupid as brutes". These "slow, dull, and stupid" natives are nevertheless capable of 
conversion "when the good sense of the teacher compensates for the stupidity of his pupils" ( $p$. $\left.62^{1}\right)$.

During the mid-1600's, missionaries in Martiniques contemplated native Caribbeans' religion. According to one (Breton 1929), "After having lived without any knowledge of God, they die without hope of salvation. It would be better for us to say that they have no religion at all, instead of describing as a cult of divinity all their trifling nonsense, superstitions, or more exactly sacrileges with which they honor all of the demons who seduce them" (p. 5, emphasis ours). Another (Bouton 1635) notes that "I believe that they do not trouble themselves with knowing what becomes of [the souls of the dead]; at least we have never been able to draw this information out of them". Notably, he acknowledges that the primary source of his ignorance is that he does not interact with them very much: "Possibly we should learn more if we were to live among them or they among us. At the present time they are greatly separated from us by inaccessible hills, so that we see them rarely and only when they come by sea to trade with the French." ${ }^{2}$ In addition to barely interacting with the target population, the ignorance behind accentuating "trifling nonsense" and minimizing any association with "any thing heavenly" should raise some doubts as to the quality of this kind of information. As we return to later, however, such sources still drive many current views of traditional religions.

Anthropology emerged as a way to come to better terms with human diversity. Of course, the academic study of human variation remained mired in the values and biases of its time, but the field's lasting contributions to the study of human culture are arguably unparalleled. One such contribution comes from E. B. Tylor, who wrote two consecutive volumes of Primitive Culture (1871a, b). Marshalling considerable evidence for the crosscultural universality of religion, across these two volumes Tylor argues that traditional peoples do, in fact, have the essential elements of religious expression in the form of belief in spiritual agents (i.e., animism). One of Tylor's lasting contributions, then, was undermining the earlier view that traditional peoples somehow lacked religion.

However, he spends virtually no time investigating whether these animistic traditions are "moralistic". When he discusses this question, he dismisses the possibility outright without a single example:

One great element of religion, that moral element which among the higher nations forms its most vital part, is indeed little represented in the religion of the lower races. It is not that these races have no moral sense or no moral standard, for both are strongly marked among them, if not in formal precept, at least in that traditional consensus of society which we call public opinion, according to which certain actions are held to be good or bad, right or wrong. It is that the conjunction of ethics and Animistic philosophy, so intimate and powerful in the higher culture, seems scarcely yet to have begun in the lower (427; our emphasis).

He continues to extol the virtues of this "conjunction of ethics and Animistic philosophy":

\footnotetext{
${ }^{1}$ The Standard Cross-cultural Sample and the Ethnographic Atlas rely on this and two other sources to code the Abipón as lacking a high god of any sort.

2 These entries are in the Human Area Relations Files (HRAF), a database of qualitative accounts of various societies from a range of sources.
} 
[I]t is clear that among its greatest powers has been its divine sanction of ethical laws, its theological enforcement of morality, its teaching of moral government of the universe, its supplanting the 'continuance-doctrine' of a future life by the 'retribution-doctrine' supplying moral motive in the present. But such alliance belongs almost wholly to religions above the savage level, not to the earlier and lower creeds (II. 361).

So, while over two volumes Tylor takes pains to demonstrate that peoples at "the savage level" have religion, he dismisses the possibility that their religions "supply moral motives" to help guide their interactions. As ethnographic inquiry progressed in the form of rigorous fieldwork (in which Tylor did not engage), this particular view would become repeatedly challenged.

Indeed, for the next century, scholars would debate the presence of moralistic religious traditions while appealing to the evolution of society. Much of the debate from the late 1800s to early 1900s was about whether or not concepts of "high gods" (e.g., the Abrahamic deity) could have evolved from notions of ancestors or other spirits (e.g., see Hartland 1898; Lang 1900 for debate about the presence of such deities among indigenous Australians). As discussed in the next section, this question has had a lasting influence on the field. There was also another aspect of this breed of progressivist evolution that dominated the intellectual culture at the time. As indicated by Tylor's claims, there was a "high a priori line that savage minds are incapable of originating the notion of a moral Maker" (Lang 1900, xiv; emphasis ours) at the time. There was, however, some resistance to this idea.

Lang (1900), for example, expresses openness to the possibility that beliefs in a spiritual "Being [with] ... high moral attributes" might even predate belief in those deities who play "silly or obscene tricks [or are] lustful and false" (xv). He details the moral character of indigenous Australians' traditions, including a handful of one deities' precepts such as directives "To share everything they have with their friends" and "To live peaceably with their friends" (181). And, to emphasize his argument that concepts of "savage high gods" likely did not evolve from other spirit concepts, he surveys considerable cross-cultural evidence of traditional peoples with gods that are either appealed to as moral paragons or which directly punish people for immoral behavior (193-210). He concludes: "Anthropology holds the certainly erroneous idea that the religion of the most backward races is always non-moral" (256). Over the next half century, anthropological observation and thought would bolster Lang's indictment by directly tying morality and ethics to traditional religion.

In fact, establishing this link became a matter of course among the leading anthropologists of religion, particularly those who promoted and engaged in long-term fieldwork. In 1936, Malinowski illustrates how obvious the association with religion and morality is:

\footnotetext{
That every organized belief implies a congregation, must have been felt by many thinkers instructed by scholarship and common sense. Yet...science was slow to incorporate the dictates of simple and sound reason... [that finds] that worship always happens in common because it touches common concerns of the community. And here...enters the ethical element intrinsically inherent in all religious activities. They always require efforts, discipline, and submission on the part of the individual for the good of the community" (in Strenski 1992: 137).
}

Here, Malinowski explicitly associates "worship" with exerting individual "effort, discipline, and submission" to benefit one's community, a conception of morality that is effectively 
synonymous with contemporary evolutionary notions (see Alexander 1987; Lightner and Purzycki, present volume). Thirty years later, Evans-Pritchard (1965) dismissed the idea that traditional populations lack gods who are moral paragons - that is, models of how to properly behave-suggesting the idea was rendered a myth thanks to the efforts of ethnographic researchers. A more general conception of "morality" comes more recently from Rappaport (1999), who argued that religion is inherently moral inasmuch as ritual itself is the behavioral encoding and sanctification of conventional rules (132-133). In sum, the reigning consensus in the anthropology of religion was that in a variety of ways, traditional populations' moral sense was inextricably linked to their religious traditions.

Something has since changed, however. Curiously, contemporary researchers debate the ubiquity of moralistic supernatural punishment and often posit the kinds of strong arguments found among earlier views, thus ignoring generations of anthropological observation and theory. While some maintain that moralistic supernatural punishment is a common if not essential part of religion, others posit that such beliefs played a role in scaling up societies to include more people and more forms of economic specialization. In other words, small-scale societies typically lack such traditions. For example, some maintain that "ancestral religions did not have a clear moral dimension" (Norenzayan 2013: 127) or that the world's traditional deities are somehow "weak" and/or "whimsical" (Chudek, Muthukrishna, and Henrich 2015). Others, however, challenge such positions and point to abundant evidence of moralistic supernatural punishment beliefs or traditions with "moral dimensions" in traditional societies (Beheim et al. 2021; Bendixen et al. 2021; Johnson 2014; 2015; Lovins 2015; Purzycki 2011; Purzycki and Sosis forthcoming; Purzycki et al. in press; Raffield, Price, and Collard 2019; Singh, Kaptchuk, and Henrich 2021).

The theories motivating such debates are wide-ranging as well (for review see McKay and Whitehouse 2015; Purzycki and Watts 2018). Some posit that forms of supernatural punishment, including the so-called "moralistic high gods" (i.e., creator deities that "support" human morality; see below) might have mitigated problems associated with cooperation (e.g., Johnson 2005; Roes and Raymond 2003; Snarey 1996). Specifically, some kinds of cooperative problems associated with social complexity or subsistence may have contributed to the evolution of moralistic high gods (Peoples and Marlowe 2012). In this view, then, moralistic supernatural punishment is an adaptation to particular conditions such as harsh environments (Botero et al. 2014) or water scarcity (Snarey 1996). In addition to adaptively responding to threats to cooperation, others suggest that moralistically punitive religious traditions may contribute to social complexity by harnessing prosocial motivations to apply to a wider range of co-religionists (M. Lang et al. 2019; Norenzayan et al. 2016; Purzycki et al. 2016). Others still argue that the so-called "moralistic traditions" were responses to-and not drivers of-the increased wealth that societies of the past enjoyed (Baumard et al. 2015; cf. Purzycki, Ross, et al. 2018) or that even environmental factors such as weather may have played an important role in the emergence of "moralistic high gods" (Skoggard et al. 2020). Given the fairly deep history of the debate, what accounts for the re-emergence of the view that traditional populations lack a "clear moral dimension"? As we detail below, part of the explanation is due to the contemporary use of data coded from the kinds of accounts that predate the anthropological turn toward learning about human variation with direct contact and fieldwork. Another contributing factor is the over-emphasis on high gods. 


\section{Turning Old Accounts into Data}

As discussed in the previous section, much of what we know about cross-cultural patterns of traditional religion comes from qualitative ethnographies, travelers' observations, and missionary reports. Written from the perspectives of these observers, these reports were subsequently coded to create large cross-cultural databases used to examine global trends in a wide variety of human activities. While valuable, when it comes to religion, there are deep problems with the data.

The most common way of assessing these questions has been to use cross-cultural databases such as the Ethnographic Atlas (EA) or Standard Cross-cultural Sample (SCCS) (Murdock and White 1969). These databases were designed to test predictions about human practices in ways that are statistically feasible and that overcome problems associated with cultural relatedness (i.e., Galton's problem). In other words, such databases convert qualitative information into analyzable quantitative data. The studies that exploit these databases find the target relationship between moralistic high gods and social complexity (Botero et al. 2014; Johnson 2005; Peoples and Marlowe 2012; Skoggard et al. 2020; Snarey 1996)

Consider again the process by which some databases have come to be. Figure 1a illustrates the causal pathways (see McElreath 2020: 515; Purzycki, Bendixen, and Lightner 2022; see Pearl, Glymour, and Jewell 2016 for more general background of causal inference) of our target prediction-namely, that social complexity causes the belief in moralistic supernatural punishment (the point still holds if we reverse this direction). In this model, we have historical reality, the "true" or "original" causal relationship between social complexity and moralistic gods we wish to infer: $S \_0-->G_{-} 0$. Of course, we do not have direct access to this reality, but it was recorded by the sources $M$ with varying degrees of fidelity and reliability. As indicated in the previous section, sources' attitudes, focus, and ignorance influenced the content of the data we can use; reports may or may not contain germane, veridical information that is subsequently converted to the corresponding data we can use for testing the hypothesis, hence, $S \_D-->G_{-} D$. While historical reality had some corresponding effect on the data we can use, given the issues of source quality discussed, it is reasonable to assume that the source of the material also has some impact on what is subsequently knowable and testable. As such, source $M$ is a central factor in the causal structure of the data's creation and therefore desirable to hold constant. Yet, even if we control for $M$ in this model, $S \_O$ remains a confounder as its influence on $G_{-} D$ works through $G_{-} O$ and $S_{-} D$. The model therefore suggests that the testable relationship between $S_{-} D-->G_{-} D$ is deeply confounded; assuming we can't control for the reality of history, the only way to de-confound an analysis in this case is to find a variable that blocks the paths from $S_{-} O_{-->} G_{-} D$. While this simple causal model is not exhaustive of the process and not necessarily representative of other cultural domains, it does suggest that the data we use for this particular question - the relationship between moralistic traditions and traditional societies-pose complications for our tests. Setting this issue aside, we can now confront how we measure the presence of the "moralistic" aspects of religion using these data.

But here we face another problem: while much of the contemporary study of religion is interested in the "moral dimensions" of religion, these data sets focus specifically on morally interested high gods. In fact, the EA and SCCS each have only a single variable pertaining to the content of religion, the "high god" variable (V34 and V238 respectively). Here, a "high god" is: 
"a spiritual being who is believed to have created all reality and/or to be its ultimate governor, even though ${ }^{3}$ his/her sole act was to create other spirits who, in turn, created or control the natural world" (cf. Swanson 1960: 210). This variable has four categorical options as possible data points:

1. absent or not reported [in the materials]

2. present but not active in human affairs ${ }^{4}$

3. present and active in human affairs but not supportive of human morality

4. present, active, and specifically supportive of human morality

5. missing data [data unavailable] (see Dow and Eff 2009 for discussion of missing data in the SCCS)

The SCCS includes 186 cultural groups in its sample. Table 1 reports the raw data. Sixty-eight of them (37\%) were coded as having high gods that are "absent or not reported." This does not necessarily mean that these populations don't have high gods. Rather, the selected works might not have mentioned the issue for a host of reasons: a) perhaps the high god wasn't important enough to have been noted by ethnographers, b) ethnographers didn't bother to ask, c) the people being studied didn't tell the ethnographer about it, or perhaps $d$ ) the authors of the materials simply rejected the idea that the target populations had such gods (see above). In other words, "absent or not reported" simply means not in the target literature describing the population ${ }^{5}$.

Furthermore, a society may have been coded as " 0 " by virtue of not having a moralistic god that was a creator or ultimate governor. In other words, a society might have had moralistic gods, just not moralistic high gods (see Section 3 for further discussion). In sum, this coding does not encapsulate contemporary questions and therefore is not an adequate source to confirm or refute the idea that small-scale societies had clear moral aspects to their gods, let alone their religious traditions.

What, then, can the SCCS data tell us about the relationship between moralistic high gods and social complexity? Out of the 186 societies, 40 (22\%) are reported to have moralistic high gods while 86 (46\%) are reported as either absent/unreported or have missing data outright. Roes and Raymond (2003: 129) treat the "jurisdictional hierarchy beyond local community" variable in the SCCS as indicative of society size. In other words, the number of recorded bureaucratic levels that are relevant for people beyond a group's closest network

\footnotetext{
${ }^{3}$ The D-PLACE data hub has altered this text to say "even if his sole act". With this apparently trivial rewording, the creation of other spirits is demoted from being a defining criterion of "high gods" to merely a possible feature. https://d-place.org/parameters/EA034\#1/30/152. Accessed November 24, 2021.

${ }^{4}$ On one page (see link in note 4), D-PLACE claims it uses Swanson's codes ("absent", "otiose", "active, but not supporting morality", and "active, supporting morality") with the EA data, but when searching for the description of the high gods variable, it defines the options like that detailed above (e.g., "absent or not reported in substantial description of religious beliefs").

${ }^{5}$ One methodological blind spot is that we simply don't know much about the process by which the qualitative data were transformed into the quantitative codes. In the case of the EA and SCCS, we do have access to the original source material. However, we have no record or much of a sense of what rules the coders used to transfer the words into numbers. Databases like Pulotu (Watts, Sheehan, et al. 2015) and the Database of Religious History (Slingerland and Sullivan 2017) prudently incorporate metadata that indicate coder confidence and source clarity.
} 
indicate how large and therefore interconnected a society is with another society, thus implying a level of greater complexity than a small-scale society that primarily keeps to itself. These data run from no levels ("no political authority beyond community") to four ("e.g., large states") levels. Here, the most common type of society is one with no such levels of hierarchy $(n=82$; $44 \%$ of the entire SCCS sample) whereas the least common is represented by societies with four levels of hierarchy (6\%). The modal society type with moralistic high gods is those with only one level of social complexity ( $n=13$, representing $7 \%$ of the entire sample).

\begin{tabular}{|c|c|c|c|c|c|c|c|}
\hline \multirow{7}{*}{ 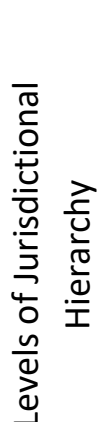 } & \multicolumn{7}{|c|}{ High God Type } \\
\hline & & $\begin{array}{c}\text { Abs./ } \\
\text { Unreported }\end{array}$ & $\begin{array}{l}\text { Present, } \\
\text { Inactive }\end{array}$ & $\begin{array}{c}\text { Present, } \\
\text { Active }\end{array}$ & Moralistic & No data & Sum \\
\hline & 0 & 43 & 17 & 8 & 6 & 8 & 82 \\
\hline & 1 & 13 & 15 & 2 & 13 & 5 & 48 \\
\hline & 2 & 4 & 6 & 3 & 7 & 3 & 23 \\
\hline & 3 & 4 & 3 & 0 & 11 & 1 & 19 \\
\hline & 4 & 4 & 6 & 0 & 2 & 0 & 12 \\
\hline & No data & 0 & 0 & 0 & 1 & 1 & 2 \\
\hline & Sum & 68 & 47 & 13 & 40 & 18 & 186 \\
\hline
\end{tabular}

Table 1. Raw frequencies of levels of jurisdictional hierarchy by high god type across all societies in the SCCS $(n=186)$. Data from DPLACE.

If we look at the proportions of society type with the various high god codes, we see patterns that are consistent with the idea that moralistic high gods are associated with social complexity (Fig. 1b). The dark bars effectively reproduce a graph in Peoples and Marlowe (2012) used to show a positive relationship between social complexity and moralistic high gods. For instance, $7 \%$ (6/82) of the societies coded with no broad hierarchy levels have moralistic high gods while $27 \%(13 / 48)$ of the societies with one level of hierarchy are coded as having such deities, followed by $30 \%$ at level $2,58 \%$ at level 3 , yet only $17 \%$ at level 4 .

However, these values are a little misleading for a few reasons. First, these are withinsociety-level proportions; $7 \%$ (Level 0) certainly looks a lot smaller than $58 \%$ (Level 3), but there are only 19 examples of Level 3 societies and 82 at Level 0 . Second, the vast majority of Level 0 societies were coded with "Absent/Unreported". In fact, the highest frequency of any of the high god codes ( $23 \%$ of all coded societies) is where simplest societies have moralistic high gods coded as "absent or not reported". In other words, nearly a quarter of the entire data set is represented by this crude code. If we treat "absent or not reported" as an index of our ignorance about these small-scale societies, our knowledge of such societies is deeply impoverished. 
(a)

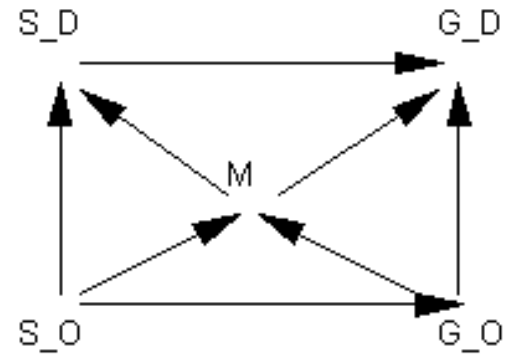

Causal Model

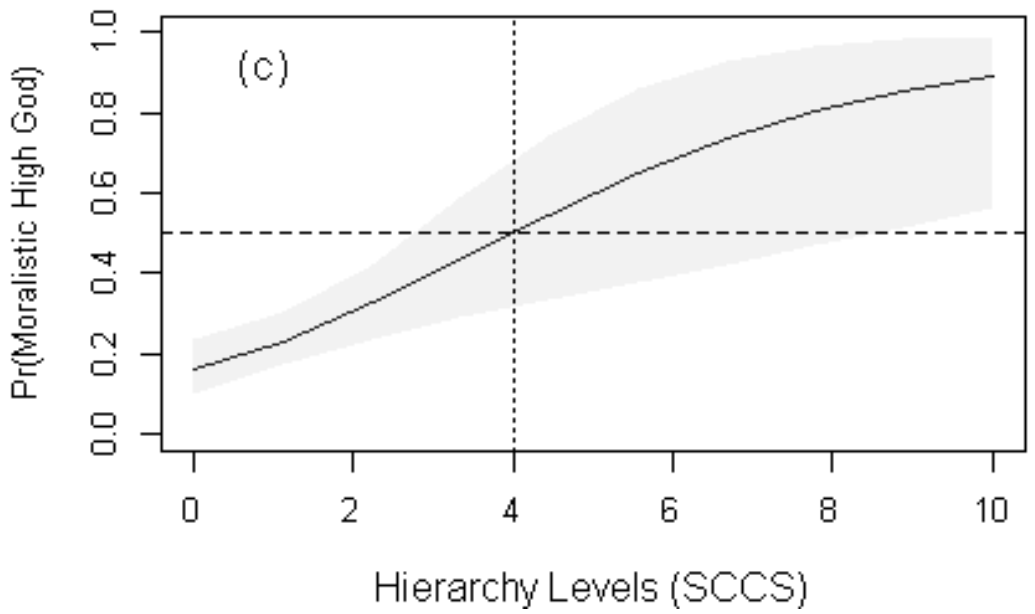

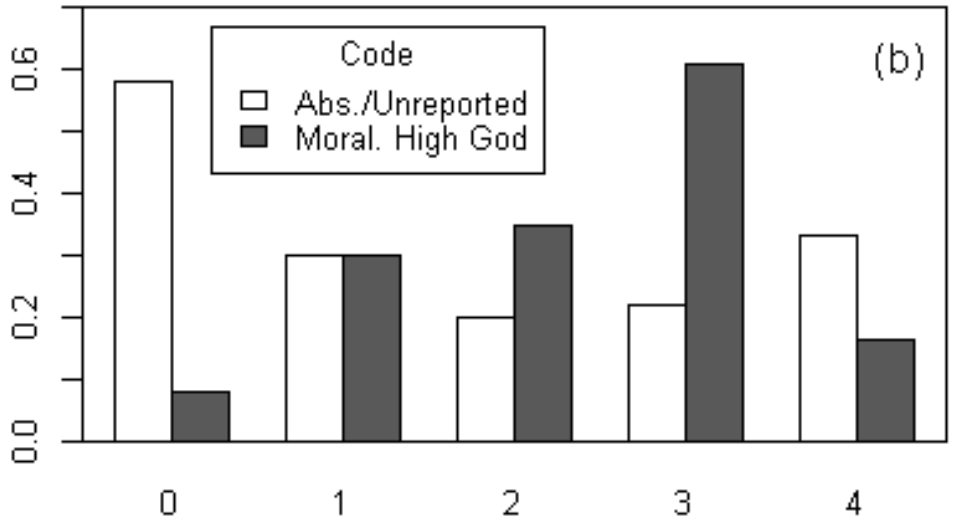

Jurisdictional Hierarchy Levels (SCCS)

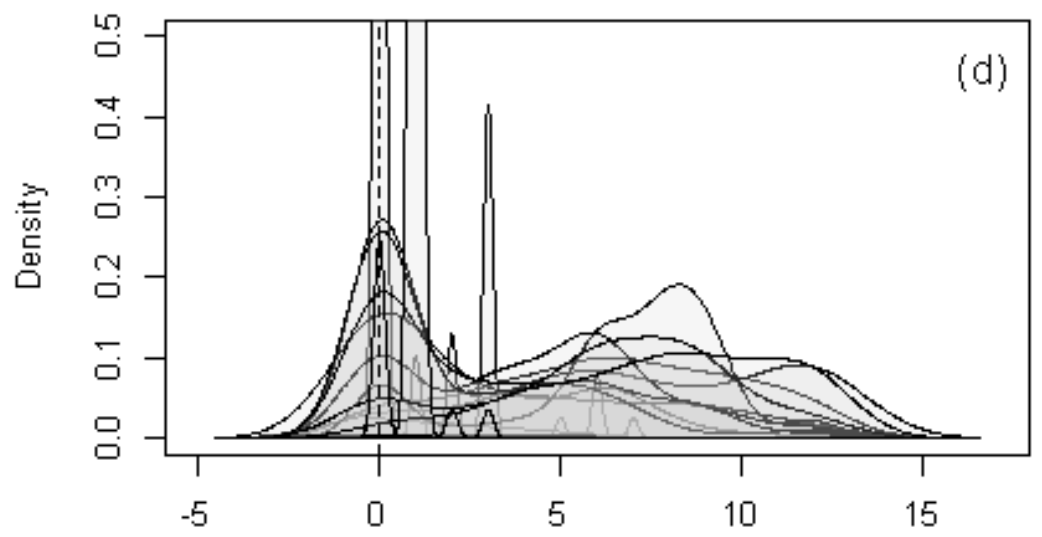

Moral Interest Scale

Figure 1a-d. (a) Causal model of original size (S_O), having a moralistic god (G_O), observer effects (M) and actual data from quantitative databases. (b) Proportions of absent/unreported (white) and moralistic high gods (gray) across levels of jurisdictional hierarchy among 186 societies in the Standard Cross-cultural Sample (SCCS). (c) Probability plot from logistic regression predicting probability of having a moralistic high god. Vertical line marks the maximum possible value in SCCS data and horizontal line marks the $50 \%$ chance. (d) Moral interest scale of "local deities" from 12 societies around the world. Data from (a) and (b) taken from DPLACE. 
Third, these proportions don't actually tell us what we want to know, namely, what the likelihood is that a society has a moralistic high god at varying levels of social complexity. Reports using these data (e.g., Botero et al. 2014; Roes and Raymond 2003; Skoggard et al. 2020) dichotomized these values, "thus creating a variable...called Moralizing [High] Gods, with two values: either supportive of human morality, or not" (Roes 2009). Consistent with these efforts, we dichotomized the high god variable so that all societies with moralistic high gods were coded with a "1" while all other societies (other than those without data) were coded as a " 0 ". We then used the jurisdictional hierarchy variable (from zero to four) to predict the probability of having a moralistic god.

In our reproduction of the essential prediction from previous studies, we too find a positive relationship. Unlike previous studies, however, we look directly at what the results mean. A simple logistic regression ${ }^{6}$ shows that the chance of the simplest societies - those with no levels of jurisdictional hierarchy beyond local communities-having a moralistic god is $16 \%$ $(95 \% \mathrm{Cl}=[0.10,0.24])$. The model predicts that as societal levels increase in number, so do the chances of having a moralistic high god. Societies with one level of social complexity have a $22 \%$ chance of having a moralistic high god, those with two levels are predicted to have a $30 \%$ chance, while those with three and four levels have a $40 \%$ and $50 \%$ chance respectively. So, ignoring the aforementioned problems associated with source quality and how it might affect the reliability of the data, we do see a steady increase in the likelihood of having moralistic high gods as the levels of jurisdictional hierarchy increases. Despite this increase, however, the model actually tells us that the chance that a society with the maximum level of social complexity - a four-has a moralistic high god is $50 \%$. In other words, a coin flip is about as useful to predict whether or not a random society with four levels of hierarchy has a moralistic high god. Based solely on this result, we shouldn't deny that there is a relationship, but we also should avoid claiming that it is a reliable or unambiguous one. Figure $1 c$ shows that if we use the model to make predictions about societies with even more levels of hierarchy beyond four, there is nevertheless a predicted, steady increase in likelihood.

To recapitulate, accounts of small-scale populations are not without problems in terms of data quality, reliability of methods, and observations peppered with the biases and sentiments of the time in which they were recorded. Furthermore, cross-cultural databases that exploit these accounts are often coded using schemes that reflect interests of the times, such as moralistic high gods rather than general moralistic supernatural punishment. A close look at the relationship between such gods and social complexity yields ambiguous results; while the relationship is positive, it is far from strong. More recent efforts recognize that specifically relying on "high gods" is too constrained to assess more recent ideas (Purzycki, Henrich, et al. 2018; Purzycki and Watts 2018; Watts, Greenhill, et al. 2015). It is partly for this reason that there has been movement toward targeted studies of "moralistic" or "broad supernatural

\footnotetext{
${ }^{6}$ We modelled the probability of having a moralistic high god binomially. We set the prior distributions for the main intercept, $\alpha$, and the coefficient for social complexity, $\beta$, as Normal $(0,1)$. According to this simple model, then, $\alpha=-1.67(95 \% \mathrm{Cl}=-2.18,-1.16)$ and $\beta=0.42(95 \% \mathrm{Cl}=0.16,0.68)$. Percentages reported in the main text use inverse-logit transformations of the relevant estimates. So, the model predicts that the chances of, for example, a society of social complexity level 4 is $50 \%$, the logistic transform of $-1.67+4 * 0.42$. A better model would treat the effect of jurisdictional hierarchy monotonically, but we keep things simple for the sake of illustration.
} 
punishment" (e.g., Watts, Greenhill, et al. 2015) in the literature instead of "high gods", a vestigial artifact of past generations' interests.

\section{Taking Another, Closer Look}

If we look at data beyond these particular sources, we find a portrait that resonates more with the anthropological view that acknowledges small-scale religions' moral relevance. Indeed, early and contemporary ethnographies as well as autobiographies of indigenous peoples not included in such databases also show indicators of various forms of moralistic supernatural punishment around the world:

- Paliyan gods: "on their own initiative punish incest, theft, or murder with an accident or illness" (Gardner 1972, p. 434; cf. 1991).

- Dogrib: "Wrongdoing [e.g., 'slacker[s], womanizer[s], and other transgressors of...norms'] might also incur the visitation of supernatural illness" (Helm 1972: 79).

- Nuer "such moral faults as meanness, disloyalty, dishonesty, slander, lack of deference to seniors, and so forth, cannot be entirely dissociated from sin, for God may punish them even if those who have suffered from them take no action of their own account" (Evans-Pritchard 1956: 193).

- San ancestor spirits (//gangwasi): "expect certain behavior of us. We must eat so, and act so. When you are quarrelsome and unpleasant to other people, and people are angry with you, the //gangwasi see this and come to kill you. The //gangwasi can judge who is right and who is wrong" (Lee 2003: 129-130).

- G/wi god's "anger is expected if some taboos are broken and as a result of certain acts...in order to show man's lack of arrogance and thereby to avoid [N !adima's] displeasure...Death and other misfortunes are sometimes attributed to his anger" (Silberbauer 1972: 319).

- Siouan religion has been indigenously characterized as forbidding "the accumulation of wealth and the enjoyment of luxury" (Eastman 1980 [1911]: 9).

- the Inuit Sedna myth is about the supernatural consequences of selfishness where white bears punish people for past people's moral transgressions (Turner 1894: 261-262).

- moralistic punishment in folktales among the Matsigenka (Izquierdo, Johnson, and Shepard Jr. 2008; Johnson 2003).

Boehm (2008) reviewed 43 ethnographies covering 18 foraging societies. In them, there are many instances of supernatural punishment of behavior construed as "antisocial" and "predatory on fellow band members" found among all 18 groups. In fact, in Swanson's (1960) classic dataset of 50 societies $^{7}$, only $6(12 \%)$ report instances of having a "moralizing high god", yet $11(22 \%)$ are counted as "uncertain". However, 68\% (34/50) of sampled populations have some documented form of "supernatural sanctions for morality", that is, "behaviors that

\footnotetext{
${ }^{7}$ Populations with less than 10,000 people comprise $78 \%$ and societies with three or fewer "sovereign organizations" comprise $74 \%$ of the sample.
} 
helped or harmed other people" (212). In Watts et al.'s Pulotu data set (Watts, Sheehan, et al. 2015), 27 of the 74 (36\%) Austronesian societies coded as "low political complexity" (acephalous or simple chiefdoms) had moralising gods.

Data like these seem to elicit a common reflex, namely, the question: how many of these examples are due to exposure to colonial and/or proselytizing religions? A common--and relatively old (Evans-Pritchard 1965; Hartland 1898; Lang 1900: xiv)-response to evidence of moralistic gods' presence in small-scale societies appeals to external influences, typically Christian missionaries. Specifically, if small-scale populations have concepts of morally concerned gods, they must have been acquired from missionaries. This view, one which EvansPritchard (1965) characterized as "condescending" (107), is a common reaction to finding cases where smaller populations have something resembling a moralistic, punitive, and knowledgeable deity. Of course, many traditional populations incorporated Abrahamic beliefs into their ways of life and/or adjusted their own beliefs accordingly. However, there is no $a$ priori reason to think that they did so systematically or that it was a one-way street (especially given the varied treatment of indigenous peoples by Christians). Ideally, researchers would have some index of exposure to imperial religions and some indicator of the kinds of relationships they forged with local populations. Indeed, there is variation across the reception of colonial traditions across society type; recent research shows that more socially complex societies are more likely to adopt the Christianity of colonial powers (Watts et al. 2018).

\section{Looking Forward}

In summary, throughout anthropology's intellectual history, the question of the development of so-called "moralistic traditions" has remained central. While early denials that traditional societies had moralistic components likely reflected a mixture of different definitions, ethnocentrism, and ignorance, they were in time overturned by more targeted efforts by anthropologists. Yet, the contemporary resurgence of commitment to the idea that small-scale religions had no moral dimensions is partly due to a heavy reliance on crudely recorded and coded qualitative data of varying reliability. Recent efforts, however, vindicate the anthropological view that moral elements of religion are not just ubiquitous but central in the ethnographic world (see Lightner and Purzycki, present volume; Bendixen and Purzycki, present volume).

In our view, the question of the relationship between social complexity and moralistic religions should remain open for these and other reasons (see McKay and Whitehouse 2015; Purzycki and Watts 2018). If using data from cross-cultural databases, researchers should ensure:

1. that key concepts (e.g., "moralistic" traditions or gods, social complexity, etc.) are operationalized clearly and validated appropriately (McKay and Whitehouse 2015)

2. clear delineation between "moralistic" and "morally relevant" (Teehan 2014)

3. that the "high god" concept is only relied on to the extent that it is relevant to one's research question

4. that important meta-data (e.g., variation in source quality due to racism, religious ethnocentrism, active knowledge of population, focus on target question; timing of source and cultural imports) is appropriately modelled (Watts et al. in press) 
The first point might seem obvious to social scientists, but it is often neglected. If the answer to the question of the relationship between social complexity and moralistic traditions really depends on our definitions, we had better be precise enough in our conception and consistent enough in our execution in order to make any project reproducible and open to scrutiny and replication. If the primary question we are to answer is about the presence or absence of religiously postulated consequences to how people treat each other, then researchers relying on the SCCS and EA should revisit the literature and not rely on the "high god" variable, which is problematic for a host of reasons we detailed in this chapter.

Another solution is to directly engage with the populations under consideration. In fact, recent direct, focused, and quantitative individual-level ethnographic inquiry into these matters shows that when individuals are directly asked if traditional gods care about punishing moral behaviors--theft, murder, and deceit-- they tend to answer affirmatively, even after holding constant any correlations with the more obviously "moralistic" traditions (Purzycki, et al. 2022). Figure $1 \mathrm{~d}$ shows that across 12 non-Western societies with varying modes of subsistence from around the world, the bulk of response distributions to a "gods' moral interest scale" about locally important deities are positive. The finding that traditional spirits are morally interested was illustrated and replicated in the Tyva Republic (Purzycki 2011, 2013; Purzycki and Kulundary 2018). Similar patterns exist across two sites in Vanuatu (Atkinson 2018) that differ in how committed they are to Christianity. No obvious differences are apparent in their ratings of how morally interested traditional gods are. We also find that when asked, the Hadza (Apicella 2018)--who have largely resisted conversion to world religions-claim two traditional deities (represented by the sun and moon) are concerned with human morality. Notably, cases where people don't show this obvious proclivity include Fiji (McNamara and Henrich 2018), where commitment to ancestral spirits is shunned and responses are at basement levels; and fullymarket integrated Mauritius (Xygalatas et al. 2018), where commitment to local spirits is forbidden. The high peaks at the lower values of the moral interest scale include these sites; high concentrations of scores of " 0 " on the scale are cases where worship of such deities is frowned upon (Bendixen et al. 2021; Purzycki et al. in press). In sum, while one contemporary view - a view which anthropologists overturned nearly a century ago - is that traditional societies lack moralistic traditions or, more specifically, gods that care about morality, we find the opposite. When asked, traditional people will ascribe some moral concern to their deities. The question of when this trait cross-culturally developed remains open.

\section{Acknowledgments}

Purzycki thanks the Aarhus University Research Foundation and acknowledges support from a Consequences of Formal Education for Science and Religion Project grant that was funded by the Issachar Fund. The authors thank Theiss Bendixen and Aaron Lightner for their feedback on earlier drafts.

\section{References}

Alexander, Richard D. 1987. The Biology of Moral Systems. New Brunswick: Aldine Transaction. 
Apicella, Coren Lee. 2018. "High Levels of Rule-Bending in a Minimally Religious and Largely Egalitarian Forager Population." Religion, Brain \& Behavior 8 (2): 133-48. https://doi.org/10.1080/2153599X.2016.1267034.

Atkinson, Quentin D. 2018. "Religion and Expanding the Cooperative Sphere in Kastom and Christian Villages on Tanna, Vanuatu." Religion, Brain \& Behavior 8 (2): 149-67. https://doi.org/10.1080/2153599X.2016.1267028.

Baumard, Nicolas, Alexandre Hyafil, Ian Morris, and Pascal Boyer. 2015. "Increased Affluence Explains the Emergence of Ascetic Wisdoms and Moralizing Religions." Current Biology 25 (1): 10-15. https://doi.org/10.1016/j.cub.2014.10.063.

Beheim, Bret, Quentin D. Atkinson, Joseph Bulbulia, Will Gervais, Russell D. Gray, Joseph Henrich, Martin Lang, et al. 2021. "Treatment of Missing Data Determined Conclusions Regarding Moralizing Gods." Nature 595 (7866): E29-34. https://doi.org/10.1038/s41586-021-03655-4.

Bendixen, Theiss, Coren Lee Apicella, Quentin Atkinson, Emma Cohen, Joseph Henrich, Rita Anne McNamara, Ara Norenzayan, Aiyana Koka Willard, Dimitris Xygalatas, and Benjamin Grant Purzycki. 2021. "Appealing to the Minds of Gods: A Novel Cultural Evolutionary Account of Religious Appeals and an Empirical Assessment Using Ethnographic Data from Eight Diverse Societies." Preprint. PsyArXiv. https://doi.org/10.31234/osf.io/tjn3e.

Boehm, Christopher. 2008. "A Biocultural Evolutionary Exploration of Supernatural Sanctioning." In Evolution of Religion: Studies, Theories, and Critiques, edited by Joseph Bulbulia, Richard Sosis, Harris, Erica, Genet, R, and Wyman, K., 143-52. Santa Margarita, CA: Collins Foundation Press.

Botero, Carlos A., Beth Gardner, Kathryn R. Kirby, Joseph Bulbulia, Michael C. Gavin, and Russell D. Gray. 2014. "The Ecology of Religious Beliefs." Proceedings of the National Academy of Sciences 111 (47): 16784-89. https://doi.org/10.1073/pnas.1408701111.

Bouton, Jacques. 1635. "Concerning The Savages Called Caribs." In An Account Of The Establishment Of The French In The Year 1635 On The Island Of Martinique, translated by Marshall McKusick and Pierre Verin. Chez S. Cramoisy. https://ehrafworldcultures.yale.edu/document?id=st13-003.

Breton, Raymond. 1929. "An Account Of The Island Of Guadaloupe." Translated by Thomas Armand de Turner. Historie Coloniale 1. https://ehrafworldcultures.yale.edu/document?id=st13-001.

Chudek, Maciej, Michael Muthukrishna, and Joe Henrich. 2015. "Cultural Evolution." In The Handbook of Evolutionary Psychology, 1-21. American Cancer Society. https://doi.org/10.1002/9781119125563.evpsych230.

Dobrizhoffer, Martin. 1822. An Account Of The Abipones, An Equestrian People Of Paraguay: Volume 2. John Murray. https://ehrafworldcultures.yale.edu/document?id=si04-001.

Dow, Malcolm M., and E. Anthon Eff. 2009. "Multiple Imputation of Missing Data in CrossCultural Samples." Cross-Cultural Research 43 (3): 206-29. https://doi.org/10.1177/1069397109333362.

Dunn, Oliver, and James E. Kelley, Jr., trans. 1989. The Diario of Christopher Columbus's First Voyage to America, 1492-1493. Norman: University of Oklahoma Press. 
Eastman, Charles Alexander. 1980. The Soul of the Indian: An Interpretation. Lincoln: University of Nebraska Press.

Evans-Pritchard, E. E. 1956. Nuer Religion. Oxford University Press.

Evans-Pritchard, Edward Evan. 1965. Theories of Primitive Religion. Oxford: Clarendon Press.

Gardner, Peter M. 1972. "The Paliyans." In Hunters and Gatherers Today, 404-47. Prospect Heights: Waveland Press.

- - . 1991. "Pragmatic Meanings of Possession in Paliyan Shamanism." Anthropos 86 (4/6): 367-84.

Hartland, Edwin Sidney. 1898. "The 'High Gods' of Australia." Folklore 9 (4): 290-329. https://doi.org/10.1080/0015587X.1898.9720470.

Helm, June. 1972. "The Dogrib Indians." In Hunters and Gatherers Today, 51-89. Prospect Heights: Waveland Press.

Izquierdo, Carolina, Allen Johnson, and Glenn H. Shepard Jr. 2008. "Revenge, Envy and Sorcery in an Amazonian Society." In Revenge in Lowland South America, 163-86. Gainseville: University of Florida Press.

Johnson, Allen. 2003. Families of the Forest: The Matsigenka Indians of the Peruvian Amazon. University of California Press.

Johnson, Dominic D. P. 2005. "God's Punishment and Public Goods: A Test of the Supernatural Punishment Hypothesis in 186 World Cultures." Human Nature 16 (4): 410-46. https://doi.org/10.1007/s12110-005-1017-0.

- - - 2014. "Big Gods, Small Wonder: Supernatural Punishment Strikes Back." Religion, Brain \& Behavior 0 (0): 25-33. https://doi.org/10.1080/2153599X.2014.928356.

- - . 2015. "Big Gods, Small Wonder: Supernatural Punishment Strikes Back." Religion, Brain \& Behavior 5 (4): 290-98. https://doi.org/10.1080/2153599X.2014.928356.

Lang, Andrew. 1900. The Making Of Religion. 2nd ed. London: Longmans, Green, and Co. http://archive.org/details/in.ernet.dli.2015.282250.

Lang, Martin, Purzycki Benjamin G., Apicella Coren L., Atkinson Quentin D., Bolyanatz Alexander, Cohen Emma, Handley Carla, et al. 2019. "Moralizing Gods, Impartiality and Religious Parochialism across 15 Societies." Proceedings of the Royal Society B:

Biological Sciences 286 (1898): 20190202. https://doi.org/10.1098/rspb.2019.0202.

Lee, Richard B. 2003. The Dobe Ju/'Hoansi (Case Studies in Cultural Anthropology). 3rd ed. Belmont: Wadsworth Publishing.

Lovins, Christopher. 2015. "Shangdi Is Watching You: Tasan and Big Moralizing Gods." Journal of the American Academy of Religion 83 (2): 464-89. https://doi.org/10.1093/jaarel/lfv002.

Malinowski, Bronislaw. 1992. Malinowski and the Work of Myth. Edited by Ivan Strenski. Malinowski and the Work of Myth. Princeton: Princeton University Press. https://www.degruyter.com/document/doi/10.1515/9781400862801/html.

McElreath, Richard. 2020. Statistical Rethinking: A Bayesian Course with Examples in $R$ and Stan. 2nd ed. New York: CRC Press/Taylor \& Francis Group.

McKay, Ryan, and Harvey Whitehouse. 2015. "Religion and Morality." Psychological Bulletin 141 (2): 447-73. https://doi.org/10.1037/a0038455. 
McNamara, Rita Anne, and Joseph Henrich. 2018. "Jesus vs. the Ancestors: How Specific Religious Beliefs Shape Prosociality on Yasawa Island, Fiji." Religion, Brain \& Behavior 8 (2): 185-204. https://doi.org/10.1080/2153599X.2016.1267030.

Murdock, George P., and Douglas R. White. 1969. "Standard Cross-Cultural Sample." Ethnology 8 (4): 329-69. https://doi.org/10.2307/3772907.

Norenzayan, Ara, Azim F. Shariff, Will M. Gervais, Aiyana K. Willard, Rita A. McNamara, Edward Slingerland, and Joseph Henrich. 2016. "The Cultural Evolution of Prosocial Religions." Behavioral and Brain Sciences 39 (January): e1 (19 pages). https://doi.org/10.1017/S0140525X14001356.

Pearl, Judea, Madelyn Glymour, and Nicholas P. Jewell. 2016. Causal Inference in Statistics: A Primer. John Wiley \& Sons.

Peoples, Hervey C., and Frank W. Marlowe. 2012. "Subsistence and the Evolution of Religion." Human Nature 23 (3): 253-69. https://doi.org/10.1007/s12110-012-9148-6.

Purzycki, Benjamin Grant. 2011. "Tyvan Cher Eezi and the Socioecological Constraints of Supernatural Agents' Minds." Religion, Brain \& Behavior 1 (1): 31-45. https://doi.org/10.1080/2153599X.2010.550723.

- - . 2013. "The Minds of Gods: A Comparative Study of Supernatural Agency." Cognition 129 (1): 163-79. https://doi.org/10.1016/j.cognition.2013.06.010.

Purzycki, Benjamin Grant, Coren Apicella, Quentin D. Atkinson, Emma Cohen, Rita Anne McNamara, Aiyana K. Willard, Dimitris Xygalatas, Ara Norenzayan, and Joseph Henrich. 2016. "Moralistic Gods, Supernatural Punishment and the Expansion of Human Sociality." Nature 530 (7590): 327-30. https://doi.org/10.1038/nature16980.

Purzycki, Benjamin Grant, Theiss Bendixen, and Aaron Lightner. 2022. "Coding, Causality, and Statistical Craft: The Emergence and Evolutionary Drivers of Moralistic Supernatural Punishment Remain Unresolved." SocArXiv. https://doi.org/10.31235/osf.io/qvjfp.

Purzycki, Benjamin Grant, Joseph Henrich, Coren Apicella, Quentin D. Atkinson, Adam Baimel, Emma Cohen, Rita Anne McNamara, Aiyana K. Willard, Dimitris Xygalatas, and Ara Norenzayan. 2018. "The Evolution of Religion and Morality: A Synthesis of Ethnographic and Experimental Evidence from Eight Societies." Religion, Brain \& Behavior 8 (2): 10132. https://doi.org/10.1080/2153599X.2016.1267027.

Purzycki, Benjamin Grant, and Valeria Kulundary. 2018. "Buddhism, Identity, and Class: Fairness and Favoritism in the Tyva Republic." Religion, Brain \& Behavior 8 (2): 205-26. https://doi.org/10.1080/2153599X.2016.1267031.

Purzycki, Benjamin Grant, Cody T. Ross, Coren Apicella, Quentin D. Atkinson, Emma Cohen, Rita Anne McNamara, Aiyana K. Willard, Dimitris Xygalatas, Ara Norenzayan, and Joseph Henrich. 2018. "Material Security, Life History, and Moralistic Religions: A Cross-Cultural Examination." PLOS ONE 13 (3): e0193856. https://doi.org/10.1371/journal.pone.0193856.

Purzycki, Benjamin Grant, and Joseph Watts. 2018. "Reinvigorating the Comparative, Cooperative Ethnographic Sciences of Religion." Free Inquiry, 2018.

Purzycki, Benjamin, and Richard Sosis. forthcoming. "Resistance, Subversion, and the Absence of Religion in Traditional Societies." In The Cambridge History of Atheism, edited by Stephen Bullivant and Michael Ruse, 2:982-1004. Cambridge: Cambridge University Press. 
Purzycki, Benjamin, Aiyana Willard, Eva Kundtová Klocová, Coren Apicella, Quentin Atkinson, Alexander Bolyanatz, Emma Cohen, et al. in press. "The Moralization Bias of Gods' Minds: A Cross-Cultural Test." Religion, Brain and Behavior.

Raffield, Ben, Neil Price, and Mark Collard. 2019. "Religious Belief and Cooperation: A View from Viking-Age Scandinavia." Religion, Brain \& Behavior 9 (1): 2-22. https://doi.org/10.1080/2153599X.2017.1395764.

Rappaport, Roy A. 1999. Ritual and Religion in the Making of Humanity. Cambridge: Cambridge University Press.

Roes, Frans L. 2009. "Moralizing Gods and the Arms-Race Hypothesis of Human Society Growth." The Open Social Science Journal 2 (1). https://benthamopen.com/ABSTRACT/TOSSCIJ-2-70.

Roes, Frans L, and Michel Raymond. 2003. "Belief in Moralizing Gods." Evolution and Human Behavior 24 (2): 126-35. https://doi.org/10.1016/S1090-5138(02)00134-4.

Silberbauer, George B. 1972. "The G/Wi Bushmen." In Hunters and Gatherers Today, 271-326. Prospect Heights: Waveland Press.

Singh, Manvir, Ted J. Kaptchuk, and Joseph Henrich. 2021. "Small Gods, Rituals, and Cooperation: The Mentawai Water Spirit Sikameinan." Evolution and Human Behavior 42 (1): 61-72. https://doi.org/10.1016/j.evolhumbehav.2020.07.008.

Skoggard, Ian, Carol R. Ember, Emily Pitek, Joshua Conrad Jackson, and Christina Carolus. 2020. "Resource Stress Predicts Changes in Religious Belief and Increases in Sharing Behavior." Human Nature 31 (3): 249-71. https://doi.org/10.1007/s12110-020-09371-8.

Slingerland, Edward, and Brenton Sullivan. 2017. "Durkheim with Data: The Database of Religious History." Journal of the American Academy of Religion 85 (2): 312-47. https://doi.org/10.1093/jaarel/Ifw012.

Snarey, John. 1996. "The Natural Environment's Impact upon Religious Ethics: A Cross-Cultural Study." Journal for the Scientific Study of Religion 35 (2): 85-96. https://doi.org/10.2307/1387077.

Swanson, Guy E. 1960. The Birth of the Gods: The Origin of Primitive Beliefs. Ann Arbor: University of Michigan Press.

Teehan, John. 2014. "Cognitive Science and the Limits of Theology." In The Roots of Religion: Exploring the Cognitive Science of Religion, edited by Professor Justin L. Barrett and Professor Roger Trigg, 167-87. Ashgate Publishing, Ltd.

Turner, Lucien M. 1894. Ethnology Ungava District. Smithsonian Institution.

Tylor, Edward Burnett. 1871. Primitive Culture: Researches into the Development of Mythology, Philosophy, Religion, Art, and Custom. London: John Murray.

Watts, Joseph, Simon J. Greenhill, Quentin D. Atkinson, Thomas E. Currie, Joseph Bulbulia, and Russell D. Gray. 2015. "Broad Supernatural Punishment but Not Moralizing High Gods Precede the Evolution of Political Complexity in Austronesia." Proceedings of the Royal Society of London B: Biological Sciences 282 (1804): 20142556. https://doi.org/10.1098/rspb.2014.2556.

Watts, Joseph, Joshua Conrad Jackson, E. Hamerslag, John H. Shaver, and Benjamin Grant Purzycki. in press. "Building Quantitative Cross-Cultural Databases from Ethnographic Records: Promise, Problems and Principles." Cross-Cultural Research. 
Watts, Joseph, Oliver Sheehan, Joseph Bulbulia, Russell D. Gray, and Quentin D. Atkinson. 2018. "Christianity Spread Faster in Small, Politically Structured Societies." Nature Human Behaviour 2 (8): 559-64. https://doi.org/10.1038/s41562-018-0379-3.

Watts, Joseph, Oliver Sheehan, Simon J. Greenhill, Stephanie Gomes-Ng, Quentin D. Atkinson, Joseph Bulbulia, and Russell D. Gray. 2015. "Pulotu: Database of Austronesian Supernatural Beliefs and Practices." PLOS ONE 10 (9): e0136783. https://doi.org/10.1371/journal.pone.0136783.

Xygalatas, Dimitris, Silvie Kotherová, Peter Maňo, Radek Kundt, Jakub Cigán, Eva Kundtová Klocová, and Martin Lang. 2018. "Big Gods in Small Places: The Random Allocation Game in Mauritius." Religion, Brain \& Behavior 8 (2): 243-61. https://doi.org/10.1080/2153599X.2016.1267033. 